\title{
Early diagnosis of the retinopathy of incontinentia pigmenti: successful treatment by cryotherapy
}

\author{
J Rahi, J Hungerford
}

\begin{abstract}
Prospective examination of the ocular fundi was carried out in the newborn female sibling of a girl with incontinentia pigmenti and bilateral retinopathy. At age 3 months the new baby's peripheral retina was found to be avascular in both eyes. At age 2 years progressive vascular proliferation at the watershed area between normal and abnormal retina led to bilateral vitreous haemorrhage. The new vessel tufts promptly regressed when the avascular area in each eye was treated by single-freeze cryotherapy and the blood in the vitreous absorbed. Cicatricial retinopathy was thereby prevented. Prospective retinal examination of newborn female siblings of children with incontinentia pigmenti is advised, with early cryotherapy recommended if progressive neovascularisation is detected.
\end{abstract}

Incontinentia pigmenti is a rare familial syndrome of ectodermal and mesodermal dysplasia. In 1926 Bloch $^{1}$ described a case of an 18-month-old girl referred to him with a diagnosis of glioma with retinal detachment for his opinion on a patchy pigmented rash. A later case report by Sulzberger ${ }^{2}$ added the suggestion that this was part of a familial syndrome of ectodermal defects.

The cutaneous manifestations may display three successive stages. The first is an erythematous vesicular rash associated with eosinophilia. Subsequently, verrucous lesions may occur and finally the characteristic rash on trunk and extremities, comprising brown splashes, streaks, or whorls of pigmentation. Pigmented lesions may occur without the preceding phases.

Some cutaneous features are usually present at birth. Histological examination of the pigmented lesions shows degeneration and depigmentation of the basal layer of the epidermis associated with numerous melanin laden macrophages and free melanin granules in the dermis. This increased dermal melanin is believed to originate in the basal epidermis and provided Bloch with a descriptive name for the condition.

Associated anomalies occur in $80 \%{ }^{3}$ of cases and include abnormalities of the central nervous system - for example, microcephaly and motor disturbances; dental, bony, hair, and cardiac anomalies have all been reported.

Protean ocular abnormalities occur in up to $35 \%$ of cases. ${ }^{4}$ Most result in severe visual handicap. Typically a retrolental mass containing detached dysplastic retina ${ }^{5}$ is seen at the time of diagnosis. In 15 to $40 \%$ of cases $^{6}$ there is a familial occurrence with an obvious female preponderance. The current view ${ }^{7}$ is of an X-linked dominant inheritance which is lethal in the male fetus.

This paper describes the ocular findings in two sisters. The older girl, known to have neurodevelopmental delay and abnormal skin pigmentation consistent with incontinentia pigmenti, presented with bilateral ocular disease with an end-stage retrolental mass in one eye. Examination of the younger child was prompted by these eye findings and allowed early diagnosis of the retinopathy of incontinentia pigmenti and subsequent successful treatment.

\section{Case reports}

CASE 1

This girl presented in October 1985 at age 7 years with a three-week history of bilateral leucoria noted by the parents. She had been born at term after a normal pregnancy and delivery with a birth weight of $2.9 \mathrm{~kg}$. There were no neonatal problems. From 8 months of age moderate developmental delay with microcephaly and abnormal involuntary movements were noted. A single patch of altered skin pigmentation was present on her left leg. She was the sixth of seven children born to Asian parents who were first cousins. Both parents were normal, as were the older five children, two boys and three girls. There were numerous consanguineous marriages in the family.

At presentation the following abnormal features were found in the left eye: a shallow anterior chamber, raised intraocular pressure, ectropion uveae, and complete fibrovascular retrolental membrane representing dysplastic retina. The right fundus showed a temporal membrane with dragging of the optic disc. Telangiectatic vessels were seen temporally associated with the membrane (Fig 1). At the time of presentation, the mother was near term in her seventh pregnancy and the parents were encouraged to attend for early ocular examination of the newborn baby.

CASE 2

The seventh child was 3 months old when she was first seen in February 1986. At this time there were no general medical problems. She had been born at term after a normal pregnancy and delivery with a birth weight of $2 \cdot 95 \mathrm{~kg}$.

The first ocular examination showed the temporal peripheral retina to be somewhat avascular, with microvascular abnormalities at the watershed area between normal and abnormal retina in both eyes. These retinal findings remained unchanged until 2 years of 


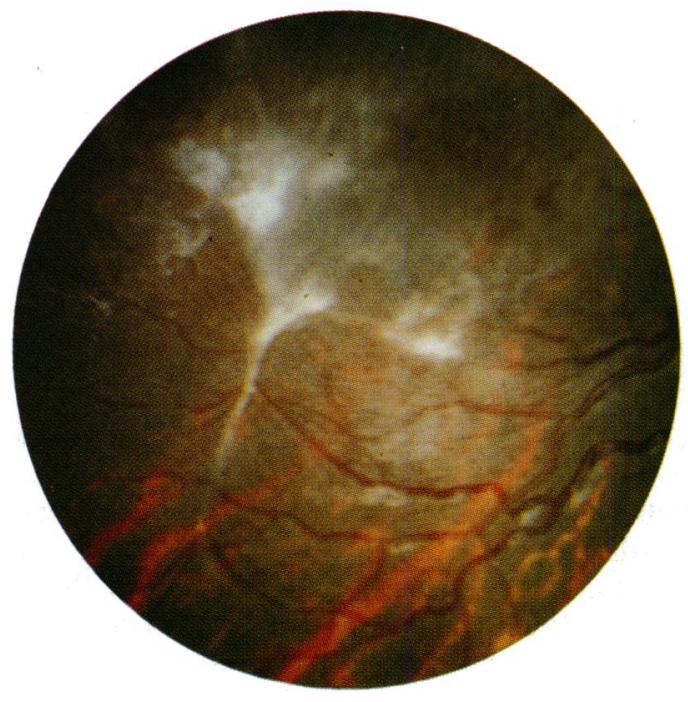

Figure 1A

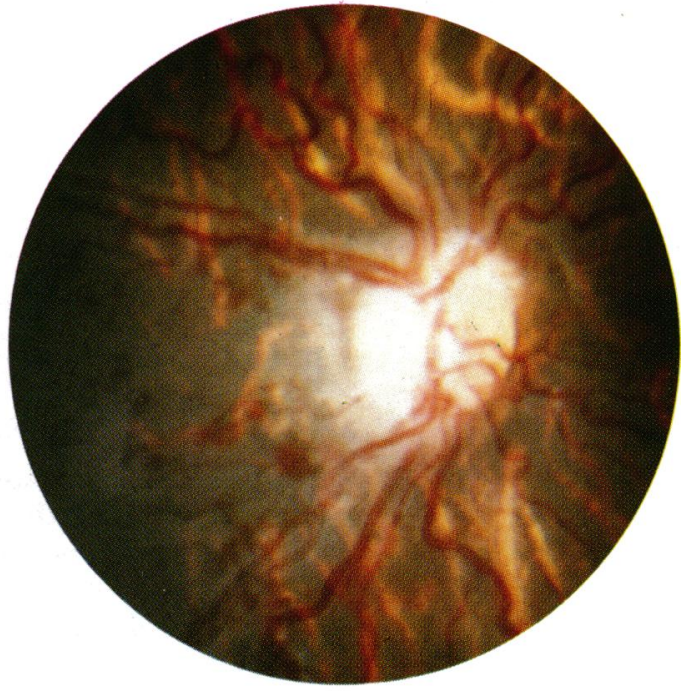

Figure 1B

Figure 1: Case 1. A: Fundus photograph of the temporal periphery of the right eye showing a fibrovascular membrane. $B:$ 'dragging of the optic disc in the same eye in association with telangiectatic retinal vessels and the temporal membrane.

age. At this time there was evidence of progression of the vascular proliferation at the margins of the avascular retinal zone, with vitreous haemorrhage in both eyes. It was considered advisable to attempt treatment by cryotherapy of the avascular retina (Fig 2). After single freeze cryotherapy of the avascular retina in the right eye bleeding promptly ceased and the new vessel tufts disappeared. Meantime the changes progressed in the left eye but promptly regressed when this eye was similarly treated. There has been no regrowth of new vessels during followup of more than 18 months. There is minimal retinal traction, and the patient appears to have normal sight.

Since the initial ocular examination this patient has been found to have microcephaly and abnormal motor development. The diagnosis of incontinentia pigmenti has been confirmed by biopsy of pigmented lesions on the trunk.

\section{Discussion}

A review by François ${ }^{8}$ of the retinal changes seen in incontinentia pigmenti describes the many abnormalities which have been reported, including retinal pigment epithelium abnormalities, haemorrhagic and pigmentary retinitis, retinal dysplasia, glial strands, retinal detachment, and optic atrophy. He concludes that they are all probably consequent upon retinal vascular changes characterised by 'ectatic veins, formation of rete mirabile and pathological venous anastomosis', and that these are the basis of the retrolental mass seen in so many cases.

The findings of Watzke $e t a l^{9}$ and Nishimura $e t$ $a l^{10}$ are consistent with our findings of the early retinal changes, and their fluorescein angiograms confirmed absence of perfusion in the areas of temporal peripheral retina beyond the zones of leaky anastomotic vessels and associated neovascularisation.

Nishimura and coworkers have described one case in which progression of vascular proliferation was arrested by photocoagulation but useful vision was not preserved because of optic atrophy and pigmentary macular change. Brown's report ${ }^{11}$ of a child followed up from the first week of life showed failure of attempted treatment with ACTH and concurred with that of François in describing pseudoglioma as the end-stage of the observed retinal vascular changes. In this context it is postulated that a retinal angiogenesis factor stimulates the neovascularisation process. ${ }^{12}$ Although the precise nature of such a factor is unknown, it is likely to be one of the several recently described by Folkman. ${ }^{13}$

The degree of retinal traction produced by the retinopathy of incontinentia pigmenti commonly differs between the two eyes, as illustrated by case 1 of the present report. The retinopathy of incontinentia pigmenti is similar in this respect to that of prematurity (ROP). As with ROP, progression of incontinentia pigmenti retinopathy ultimately slows or ceases without treatment, and it must be questioned whether the

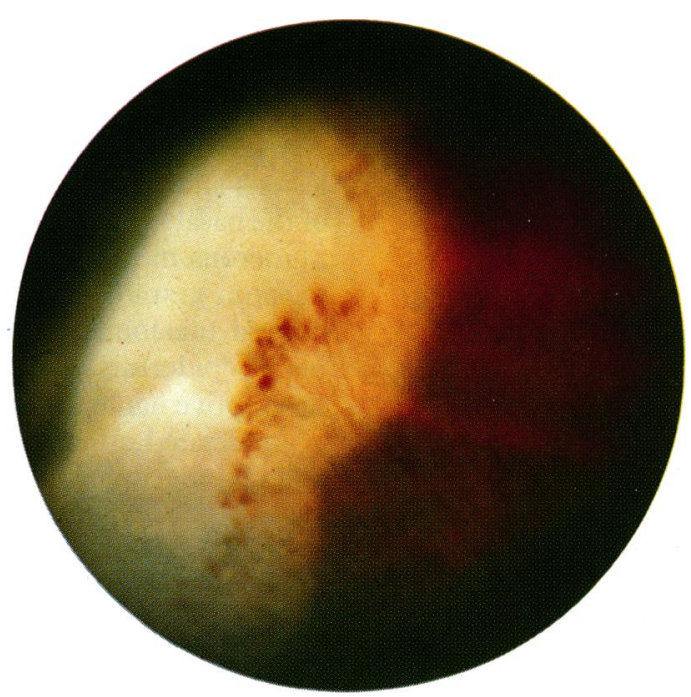

Figure 2: Case 2. Fundus photograph of the temporal periphery of the right eye showing vascular proliferation at the margin of the zone of avascular retina. The fronds of new vessels are highlighted by oedema from single freeze cryotherapy. 
arrest of progress in case 2 was the result of cryotherapy or whether it occurred spontaneously. The rapid disappearance of new vessels and haemorrhage after cryotherapy in the first treated eye coincided with continued deterioration of the fellow eye, which was in turn rapidly reversed by treatment. These features and the ultimate lack of retinal traction compared with that seen in the sibling are compelling reasons to count case 2 as a treatment success.

As for ROP, early detection of new vessels is of paramount importance in incontinentia pigmenti retinopathy. If progressive neovascularisation threatens cicatricial retinopathy, treatment must be instituted early if it is to prevent retinal detachment. Experience from the cases reported indicates that the visual deficit of incontinentia pigmenti may be limited if female siblings of affected children are screened. We advise examination within a month of birth and repeat examinations at three-month intervals, even if there is no extraocular evidence of incontinentia pigmenti. If there are no retinal signs of the disease by 1 year of age, it is unlikely to develop later. Examination may need to be more frequent if retinal ischaemia and neovascu- larisation are detected, and treatment must be instituted at the first signs of progression.

1 Bloch B. Eigentumliche, bisher nicht beschriebene Pigmentaffekian. Schweiz Med Wochenschr 1926; 56: 404.

2 Sulzberger MB. Uber eine bisher nicht beschriebene congenitale Pigmentanomalie. Arch Dermatol Syphilis (Berl) 1928; 154: 19-32.

3 Carney RG. Incontinentia pigmenti: a world statistical analysis. Arch Dermatol 1976; 112: 535-42.

4 Findlay GH. On the pathogenesis of incontinentia pigmenti with observations on an associated eye disturbance resembling retrolental fibroplasia. Brf Dermatol 1952; 64: 141-6.

5 Carney RG, Carney RG Jr. Incontenentia pigmenti. Arch Dermatol 1970; 102: 157-62.

6 Morgan JD. Incontinentia pigmenti. Am Dis Child 1977; 122: 294-300.

7 Gordon H, Gordon W. Clinical and genetical studies of two familial cases of incontinentia pigmenti. Dermatologica 1970; 140: $150-68$.

140: $150-68$.
8 François J. Incontinentia pigmenti and retinal changes. $\mathrm{Br} \mathcal{J}$ Ophthalmol 1984; 68: 19-25.

9 Watzke RC, Stevens TS, Carney RG. Retinal vascular changes of incontinentia pigmenti. Arch Ophthalmol 1976; 94: 743-6.

10 Nishimura N, Oka Y, Takagi I, Yamana T, Kitano A. The clinical features and treatment of retinopathy of BlochSulzberger syndrome. F pn f Ophthalmol 1980; 24: 310-9.

11 Brown CA. Incontinentia pigmenti: the development of pseudoglioma. Br F Ophthalmol 1988; 72: 452-5.

12 Taylor CM, Weiss JB, Kissun RD, Garner A. The effect of oxygen tension on the quantities of procollagenase activating angiogenic factor present in the developing kitten retina. angiogenic factor present in the
Br $\mathcal{F}$ Ophthalmol 1980; 70: 162-5. 13 Folkman J. Successful treatment of an angiogenic disease.
New Engl f Med 1989; 320: 1211-2. 